\title{
MANAGERIAL STYLE AND ITS MANAGERIAL IMPLICATIONS FOR ORGANIZATIONS IN THE SLOVAK REPUBLIC
}

\author{
Branislav Vargic ${ }^{1}$, Stanislava Luptakova ${ }^{2}$ \\ Faculty of Management at Comenius University, Odbojdrov 10, P.O. Box 95, 82005 Bratislava 25, Slovakia E-mail: \\ 'branislav.vargic@fm.uniba.sk; ${ }^{2}$ stanislava.luptakova@fm.uniba.sk
}

Received: 22 November, 2002

\begin{abstract}
The article presents outcomes of a survey focusing on a style of management in Slovak organizations, using Blake \& Mouton's managerial grid. The results presented ate based on a survey, consisting of a sample of 512 questionnaires addressing all managerial levels in Slovak companies. The corporations included in the survey are from various industries and fields of business as well as of different financial and capital ownership structures. The main objective of the survey is to portray management style of the managers in Slovakia from the perspective of managerial grid, analyzing people or task orientation in their managerial work. Further, the paper illustrates the differences in management style regarding the gender and the capital ownership of the company and depicts the consistency of the management style in relation to subordinates with the preferred management style from the superiors.
\end{abstract}

Keywords. Organizational behavior, managerial grid, management style, communication style, egalitarian and tournament system of society, Slovakia

\section{Introduction}

Since the political changes in the late 1980 's, the style of management performed by managers in Slovakia has altered dramatically. This transformation of managerial style, for the most part, stemmed from the considerable changes of the business environment over the past decade and caused a significant turnaround in management in Slovakia; shifting from an egalitarian towards a tournament system. There has been higher salary dispersion within organizations, increase in performance related compensation systems, more dynamic movement of people among jobs, and less stress on seniority in preference for the quality of work [1]. Thus the managers have to encompass new roles and enrich their management style by new human resource activities. They need to combine the role of mentor and counselor with the role of supervisor and leader. They need to approach their employees in a different way, to assess performance regularly and make decisions about promotion on a basis of competence and skill rather than loyalty and age.

These changes have resulted mainly from the pressures for increased competitiveness and from the demands 36 caused by the entry of foreign companies into the Slovak market, bringing often more efficient ways to manage performance. In the past, the top-down design of the society also defined the authoritarian attitude of superiors, with participative decision making almost non-existent. The recent changes to tournament system, on the other hand, demand greater flexibility from both managers and the people they manage, and require greater orientation toward the market. Based on this premise, our expectation is that the style of managing people has shifted from an autocratic and technocratic one to a consultative and cooperative one.

This bears further implications for the human resource management system within organizations to adjust to the different needs that arise from such changes. If the shift in managerial style has occurred mostly as a result of external pressures, then the successful transition toward a new style of managing people should be reflected in the system of managing performance within organizations, in the development of skills, and training programs offered by companies. 


\section{Managerial Grid}

The style of management plays an important role in defining the priorities of managers and reflects their values and attitudes towards the jobs they perform and the subordinates they manage. As studies suggest some managers have a tendency to incline to meeting their goals, while others stress the well being of their subordinates [2]. Based on these two major orientations, a managerial grid has been defined.

Robert Blake, Jane Mouton and their associates, in their desire to classify an 'ideal' leader or manager, developed the first concept of the grid. In their search for an ideal leadership/managerial style, 1(X) experienced managers were asked to select the best way of handling 12 managerial situations. As the results of their research have shown, there appeared to be two significant ways of dealing with the situations - one dealt with the attitude of managers towards achieving the set objectives and the other with the way people are treated by them. As a result of their study, the managerial grid (later renamed to the leadership grid $($ ) has been created. It maps the importance managers put on either achieving goals or satisfying people. These two aspects, however, are not mutually exclusive - a person may score high both on 'the people side' and 'the goal side', as well as the exact opposite, he or she may score extremely low on both aspects. Managers may also score high on goals and low on people aspects or vice versa. The managerial grid reflects the preference in orientation of manager's style toward goals and/or people and thus classifies the managerial style.

The Grid by itself is a matrix formed by the intersection of two behavioral dimensions - concern for production (task orientation) and concern for people (socio-emotional orientation). Thus, it presents variables of two kinds, attitudinal and conceptual with behavior descriptions connected to the rationale that lies beneath managerial actions [3]. It provides a visual framework for understanding various approaches to management and consequently presents a conceptual frame of reference for guiding the organization development process through various states: individual development, team building, conflict solving and strategic modeling, among others.

This widely known grid concept focuses on five fundamental styles: Team management, where work accomplishment is from committed people and interdependence created through a common stake in organization's purpose which leads to relationships of trust and respect (on the grid representing both high concern for goals and high concern for people); Management through authority and compliance, where operational efficiency results from arranging working conditions so that human elements interface only minimally (high concern for goals, low concern for people); Country $\mathrm{Club}$ management characterized by thoughtful attention to people's need for satisfying relationships leading to a comfortable, friendly organization atmosphere and work tempo (high concern for people low concern for goals); Middle of the road management, based on a belief that organizational performance is possible by balancing the necessity of production with maintaining a satisfactory level of morale (medium concern for both goals and people); Impoverished management, when the general conviction is held that the exertion of minimal effort to get required work done is appropriate to sustaining organizational membership (low concern for both people and goals) [4].

Despite individual preferences towards a style of management influenced by personality or attitudes, certain situational factors and culture may impact or favor the preference of a style of a manager. For example, cultures with high power distance and high uncertainty avoidance may welcome more authoritarian style, whereas collectivistic cultures may pay more attention to relationships.

\section{Research}

\subsection{Aim of the Research}

Our research focuses mainly on the identification of managers' orientation on goals and/or people; thus, identifying the performed style on a managerial grid in the Slovak Republic. Although a managerial grid is predominantly used to portray individual style, we looked at a large sample of managers at all levels of management to show a preference in managerial style on a larger socio-national scale. Our goal was to define the tendencies of managers working in the Slovak business environment, against the criteria of the managerial grid and thus characterize a preferred management style of the whole sample of participants (as stated in hypothesis 1).

In its partial aims, we investigated possible differences in managerial style when comparing male and female managers and also searched for possible variations in managerial style of managers working for Slovak companies with those of foreign origin operating in Slovakia believing that the change of external environment has caused change in management style, hence managers working for international companies will demonstrate a different style (as stated in hypothesis 2 and 3 ). 
Furthermore, in our data analysis, we looked at whether the style of management of a particular manager corresponds with his/her style of followership, seeking consistency in the behavior of managers in Slovak organizations during managerial situations. Here, the underlying assumption is that what managers believe is important to their boss, in terms of orientation toward goals or relationships in the workplace, is as important to their own style of managing subordinated. This would demonstrate a strong tendency to sustain the current style of management.

More over, in this part of our analysis, we have studied the preferences of managers to maintain relationships with superiors or subordinates outside the workplace, and thus to either favor the 'relationship oriented' management style or by neglecting such relations concentrating their managerial executive activities solely on fulfilling the goals.

Both, the analysis of the managerial style consistency downward and investigation of the managerial preferences to maintain relationships outside of the workplace were used support to our original findings.

Finally, in the conclusion, we look for the implications in terms of enhancing skills and competencies of managers and also in terms of further development, implementation and focus of the practices of human resource management. We suggest which managerial skills and competencies may need to be enforced in order to be more efficient and also which human resource management activities need to be used in order to support gaining and sustaining the optimum level of skills and performing the optimum managerial style.

\subsection{Statement of Hypotheses}

Based on the previously mentioned issues, the following hypotheses were formulated:

(HI) shift of an external environment towards tournament system of management has resulted in team management style in Slovakia;

(H2) there will not be significant differences between males and females in their managerial style;

(H3) there will be differences in managerial style based on the ownership of the company.

Hypothesis 1 embodies our expectation that the managerial style in Slovakia, as of today, is both highly concerned for goals as well as people.

Hypothesis 2 represents our belief, that because of a long history of female employment in Slovakia from the pre-1989 era, men and women react to external changes in a comparable fashion and will assume similar roles and similar preferences concerning management style.

Hypothesis 3 is based on a premise that foreign companies entering the Slovak business environment and applying their managerial style will more profoundly influence the managers whose style of management will thus differ from the style executed in local companies.

Based on our findings, in the following paragraphs we present the style of management demonstrated by the sample of managers and discuss whether there is a shift in management style from a technocratic one, based on technical skills and knowledge of managers and demonstrated in an authoritarian way (which was common in the past) toward more cooperative and consultative style, more suitable for managers generalists (and more fitting for the contemporary external environment situation).

\subsection{Research Questionnaire}

To examine the style of managing people, we have created a questionnaire that was comprised of three parts.

The first section focuses on the demographics of the respondents, asking their gender, position in the company (top, middle, line level management); type of ownership (Slovak or with foreign capital investments); tenure (1 year, 2-5 years, 6-12 years, 13+ years); the number of employees in the company as well as the number of their direct subordinates. We have also asked the respondents to identify their age by choosing one of the following categories: less than 30 years of age, 31-45, and 45+. However, as the youngest category is very small (only $12.52 \%$ of the sample), we do not believe this would be sufficient to indicate a significant difference in managerial style.

The second part of the questionnaire consists of 30 statements evaluated on a $1-5$ Lickert scale, where ' 1 ' indicates the least acceptance of the statement and '5' indicates that the respondent fully agrees with the statement. There are various statements from different areas that evaluate the attitudes of managers towards their work, their managerial style, and communication style.

For the purpose of this paper, those statements are analyzed that deal with management style.

The third part of the questionnaire consists of questions where the respondents have been asked to evalu- 
ate statements qualitatively, indicating the responses that are the closest to what they think about the statement. There has also been space available for their individual responses. For the purpose of this paper, only those questions from the questionnaire are analyzed that are relevant to the topic of managerial style preferences and either support or decline our hypotheses.

\subsection{Demographics of the Respondent Group}

The total number of questionnaires sent was 718. They were sent to 52 companies with a final count of returned filled-out questionnaires amounting to 512 from 35 organizations. This represented a $71.31 \%$ return rate on individual participants and $67.3 \%$ on the companies. The enterprises actively involved in the research cumulatively employ 11,765 people. We consider this sample more than sufficient for analysis.

The demographic characteristics of the respondent group were as follows. There were $115(22.55 \%)$ top managers, $205(40.2 \%)$ middle managers, and 190 $(37.25 \%)$ line managers. The group consisted of 390 (76.32\%) male respondents and $\mathbf{1 2 1}(23.86 \%)$ female. Out of the sample, $64(12.52 \%)$ were younger than 30, $190(37.18 \%)$ were from the group 31-45 years of age, and $257(50.3 \%)$ people were older than 45. There were 432 respondents from Slovak companies and 78 from those with capital investments from abroad (2 did not identify or were of mixed capital structure). There were 511 respondents who identified their tenure, out of which $33(6.46 \%)$ have worked less than one year for a company, $101(19.77 \%)$ who work 2-5 years with the company, $123(24.07 \%)$ who work
6-12 years with the company, and 254 (49.71\%) who work longer than 13 years with the company.

\subsection{Survey Data}

From the second part of the questionnaire, we extracted the following statements (with a scale ranging from 1 representing the statement 'never' to 5 representing 'always') related to depicting managerial style:

9. The role/goal of a manager is to take care of his/ her subordinates.

\section{For me as a manager, fulfilling goals is the pri ority.}

These two questions formed the basis for managerial grid analysis. The results are graphically analyzed in Figure 1 and show the main tendency of participants to engage in either goal oriented and/or people oriented style of management. Each participant is shown in the graph as a point with two coordinates representing Lickert scale value of question number 9 and simultaneously question number 10 .

The more respondents indicating the same pair of answers, the larger is the volume of the circle in the graph. The number shown by each circle represents the total number of respondents.

From the analysis we can decipher that most responses are clustered in the top right corner of the first quadrant. This implies that most combinations of answers indicate both concern for achieving organizational goals and concern for people. As such, this suggests that the managers are cooperative and focused on fulfilling their tasks at the same time, which proves our

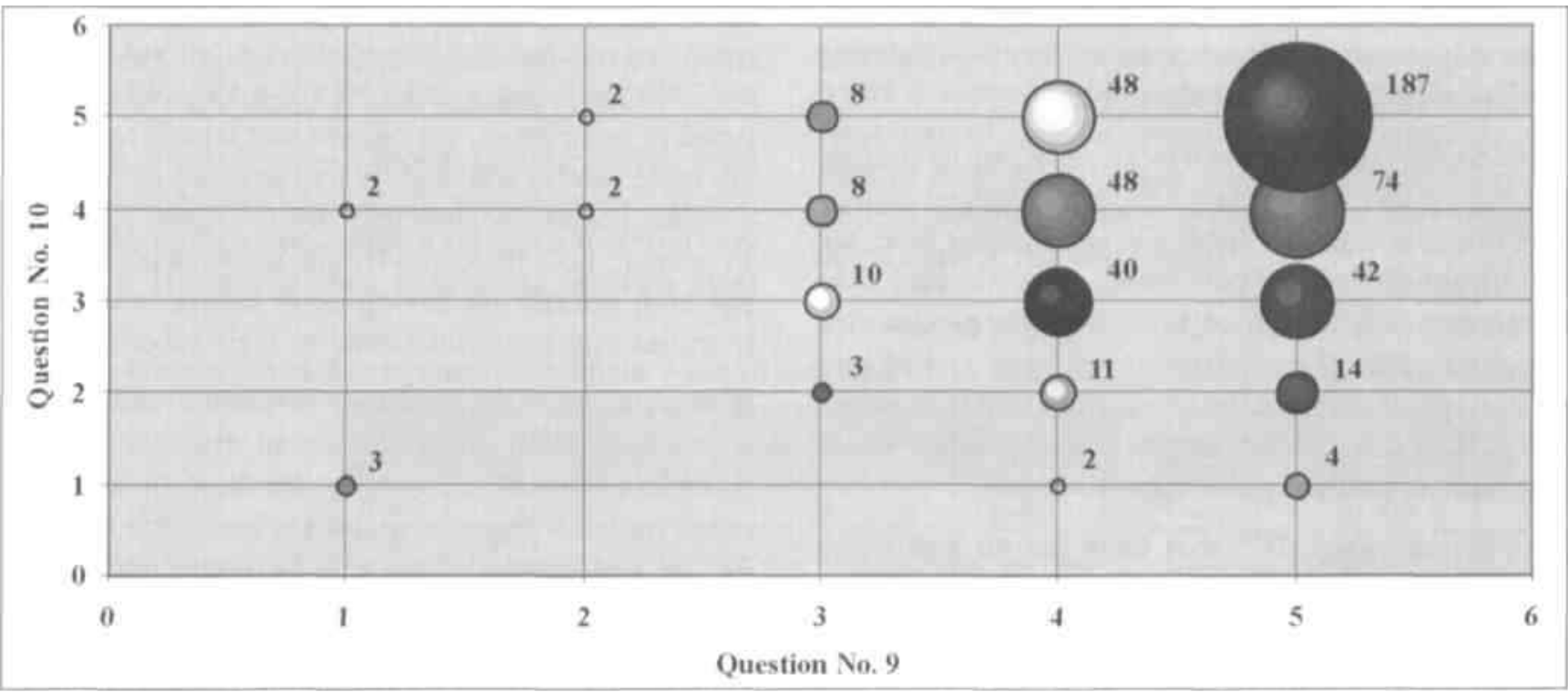

Fig 1. Managerial Grid 
Table 1. Comparison of responses to questions 9 and 10 according to the respondent gender

\begin{tabular}{|c|c|c|c|c|c|c|c|c|c|c|c|c|}
\hline \multirow[b]{2}{*}{ Answer } & \multicolumn{6}{|c|}{$\begin{array}{c}\text { Question } 9 \\
\text { The roleigoal of a manager is bo take care of hisher } \\
\text { subordinates }\end{array}$} & \multicolumn{6}{|c|}{$\begin{array}{l}\text { Question } 10 \\
\text { For me as a manager, fustiling the goais is the priority }\end{array}$} \\
\hline & Male & $\%$ & Female & $\%$ & Overall & $\%$ & Male & $\%$ & Female & $\%$ & Overall & $\%$ \\
\hline Never & 6 & 1.5 & 3 & 25 & 9 & 1.7 & 5 & 1.28 & 0 & 0 & 5 & 09 \\
\hline Almost never & 22 & 5.6 & 6 & 5 & 28 & 5.5 & 4 & 1.0 & 0 & 0 & 4 & 0.78 \\
\hline Sometimes & 68 & 17 & 24 & 20 & 92 & 18 & 20 & 5.1 & 9 & 7.5 & 29 & 5.7 \\
\hline Almost always & 105 & 27 & 29 & 24 & 134 & 26 & 119 & 30.5 & 30 & 25 & 149 & 29.3 \\
\hline Always & 188 & 48.32 & 57 & 47.9 & 245 & 48 & 241 & 62 & 80 & 67 & 321 & 63.18 \\
\hline Total & 389 & 99.42 & 119 & 99.4 & 508 & 992 & 389 & 9988 & 119 & 99.5 & 508 & 99.86 \\
\hline
\end{tabular}

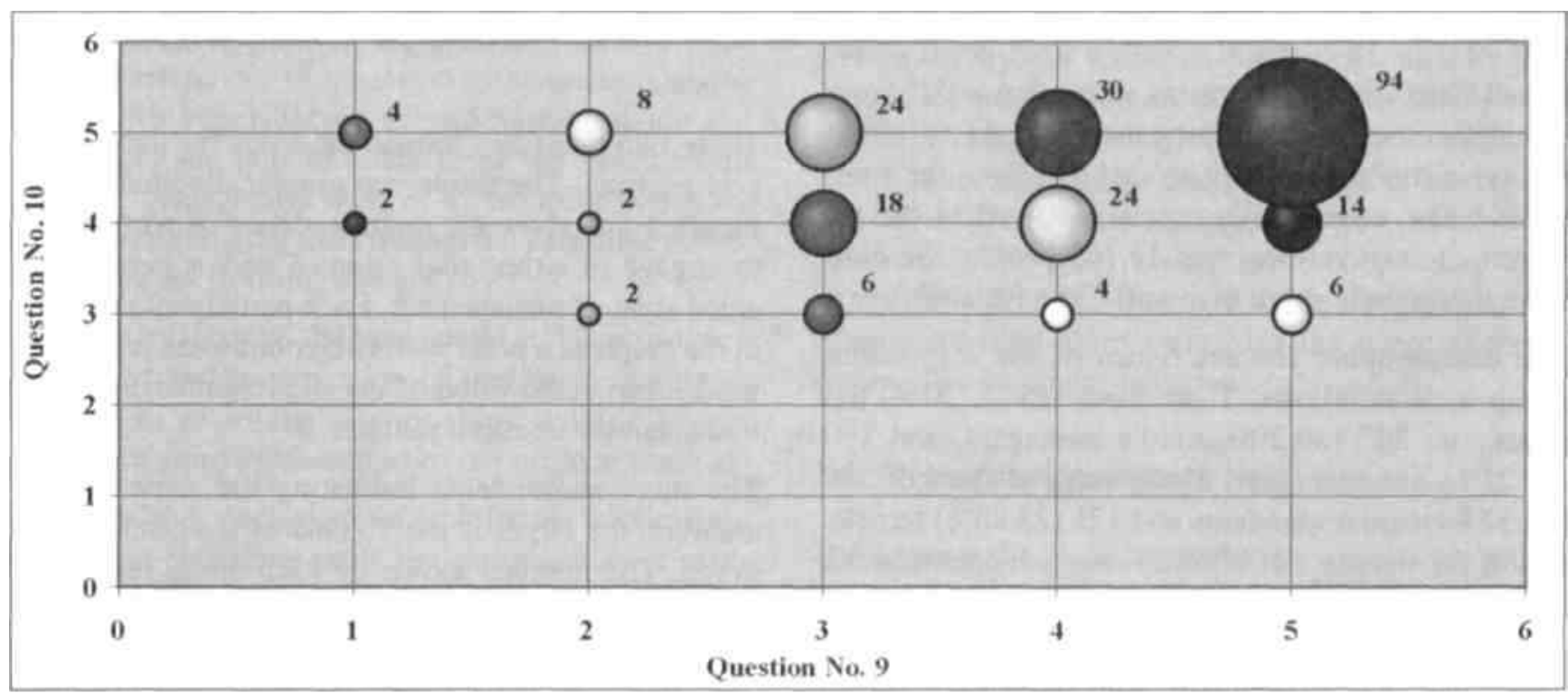

Fig 2. Managerial Grid from female responses

hypothesis (H1) that the preferred managerial style is team management with strong commitment to goals as well as emphasis on relationships at the workplace. This is in line with other findings, which show that communication style in the Slovak business environment might be considered open and both welcoming and encouraging of feedback (5].

To understand the examined topic better, we have studied this group of data against the hypothesized ownership origin and gender criteria to see whether there are significant differences concerning demonstrated style of management. Moreover, to have a more precise idea about the style of management, we have looked into several questions from the last section of the questionnaire. Their detailed explanation is used as an argument to either support or reject the main graph.

It is hypothesized $(\mathrm{H} 2)$ that there are no significant differences in responses of males and females. When comparing the data divided into two groups by gender, we do not see a significant difference in style in the gender category. While $48 \%$ of all respondents indicate that the role of a manager should 'always' be to care about their employees (question number 9) and additional $26 \%$ indicate 'almost always', when comparing female and male respondents the percentage values are $47,9 \%$ and 48,32 respectively indicating the most extreme answer. The values for 'almost always' are $24 \%$ for females and $27 \%$ for males. When compared in more detail, we can see that female responses are more careful and slightly less grouped towards the extreme positive answer than are the males' answers. In general, both male and female respondents seem to put high priority on having good interpersonal relationships and being interested in their subordinates.

When looking at the responses to question number 10, which asks about the preference of managers toward goals, it seems that the females are more strongly oriented on goals than the males (as presented in Table 1). We can conclude that also by noting there were no responses in the opposite pole of 'never' and 'almost never', whereas we found some male respondents' answers here. This can imply that female managers are more strongly oriented on goals, when ex- 
amining their goal orientation, then the male managers. In the most extreme position on always concentrating on goals, the overall percentage of answers was $63,18 \%$ whereas the female answers were of the value of $67 \%$. However, when compared the 'almost always' category, the overall response percentage is $29.3 \%$ whereas the female value is $25 \%$. We can therefore conclude that the general tendency to indicate a positive attitude towards achieving goals and putting this as a priority is the same for both genders.

To illustrate the managerial style as such, we have created a managerial grid for female responses (Figure 2) to see the combinations of responses for the questions 9 and 10. As can be seen when comparing Figure 1 and Figure 2, the style of management can be defined as open, communicative, participative and goal oriented. As such, this style is ideal for team-oriented work and for situations, which require flexibility and cooperation. It is also important to note, that the style does not change by gender and, as hypothesized, there are no differences in priorities and/or attitudes towards subordinates, colleagues, and work assignments between male and female managers.

Our last hypothesis (H3) suggests there are differences in responses based on the ownership of the company. This hypothesis stems from the consideration of different approaches and practices to managerial style that foreign companies brought and introduced in the Slovak business environment. When comparing the data divided into two groups based on capital structure, we observe slight differences in the managerial style. While almost half of all respondents from Slovak companies (49.76\%) indicate that the role of a manager should 'always' be to care about their employees and an additional 25\% indicate 'almost always', when looking at the responses from the foreign companies, the percentage values are $40 \%$ for the answer 'always' and $31 \%$ for 'almost always'.

A more detailed analysis shows, that the Slovak managers incline more towards the most extreme answer, while the foreign ones show a bit more reserved perspective. However, when combining the two most extreme responses, accumulatively the differences are of little significance.

When looking at the responses to question number 10, which asks about the preference of managers towards goals, the tendency of foreign managers to take a bit more reserved approach, as seen in responses to question 9 is maintained (as presented in Table 2). In the most extreme position indicated by the response 'always', the overall percentage of answers for Slovak managers was $66 \%$ whereas the answers of foreign managers amounted in $48 \%$.

However, when compared the 'almost always' category, this response was marked by $27 \%$ of Slovak managers in comparison to $40 \%$ of foreign managers. Hence, we can therefore conclude that the general tendency to indicate the positive attitude towards achieving goals and putting this as a priority is the same for both Slovak as well as foreign managers.

To illustrate the managerial style, we have created a managerial grid for responses from companies of foreign ownership (Figure 3) to see the combinations of responses for the questions 9 and 10 based on the ownership criteria. Again, the style of management can be defined as open, communicative, participative and goal oriented. To conclude, our hypothesis (H2) was disproved. The findings indicate that the managerial style does not vary significantly in Slovak companies in comparison to the foreign ones. This could be due to the change of the Slovak business environment and the necessity of the Slovak companies to 'catch up' if wanting to stay competitive.

\section{Support Data Analysis}

After designing the main managerial grid, we were interested in whether the main tendency of the managers is supported by further evidence. Therefore, we have looked into the questions asking about the nature of their relationships with subordinates and superiors and their preference to maintain work relationships outside the workplace.

Table 2. Comparison of the responses to questions 9 and 10 according to the structure of capital ownership of the company

\begin{tabular}{|c|c|c|c|c|c|c|c|c|c|c|c|c|}
\hline & \multicolumn{6}{|c|}{$\begin{array}{l}\text { Question } 9 \\
\text { The rote/goal of a manager is to take care of his/her } \\
\text { subordinates" }\end{array}$} & \multicolumn{6}{|c|}{$\begin{array}{l}\text { Question } 10 \text { Tor me as a manager, } \\
\text { fulfilling the goals is the priority* }\end{array}$} \\
\hline Answer & Slovak & $\%$ & Foreign & $\%$ & Overall & $\%$ & Slovak & $\%$ & Foreign & $\%$ & Overall & $\%$ \\
\hline Never & 8 & 1.8 & 1 & 1.2 & 9 & 1.7 & 4 & 0.9 & 1 & 1.2 & 5 & 0.9 \\
\hline Almost never & 20 & 4.6 & 8 & 10.4 & 28 & 5.5 & 3 & 0.6 & 1 & 1.7 & 4 & 0.78 \\
\hline Sometimes & 79 & 18 & 13 & 16.9 & 92 & 18 & 22 & 5.1 & 7 & 9 & 29 & 5.7 \\
\hline Almost always & 109 & 25 & 24 & 31 & 134 & 26 & 117 & 27 & 31 & 40 & 149 & 29.3 \\
\hline Always & 214 & 49.76 & 31 & 40 & 245 & 48 & 284 & 66 & 37 & 48 & 321 & 63.18 \\
\hline Total & 430 & 99.16 & 77 & 99.5 & 508 & 99.2 & 430 & 99.6 & 77 & 99.9 & 508 & 99.86 \\
\hline
\end{tabular}




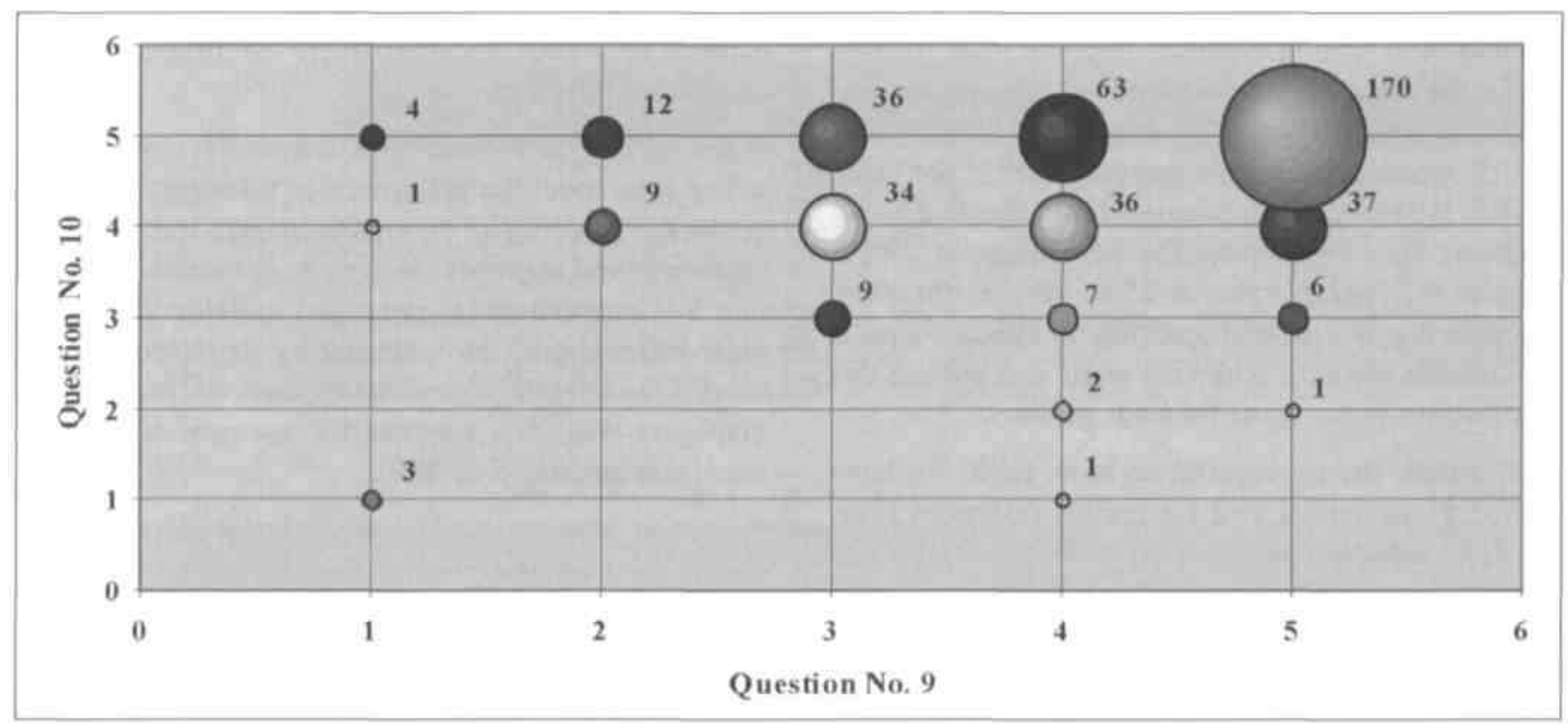

Fig 3. Managerial Grid from responses of managers from companies of foreign ownership

Each question provided a set of answers and the respondents could have indicated multiple answers, best representing their opinions. Moreover, when asking about the characteristics of the relationship, we paired the questions to check whether the managers exert the same style both towards their subordinates and their supervisors (questions 31 and 35). The same approach was applied when asking about maintaining work relationships outside of the workplace (questions 39 and 41). As the managers could identify multiple answers here, we were looking for a correspondence of managerial and followership styles of the particular manager. We believe, this fact could indicate a consistency in managerial style.

\subsection{Relationships to Subordinates and Superiors}

Questions inquiring about the characteristics of the relationship to the subordinates and superiors were as follows with the same possibilities for answers:

Question 31: The relationship to my subordinates could he best characterized as

Question 35: The relationship to my superiors could be best characterized as
a) friendly and open
b) professional hut friendly
c) professional
d) impersonal

Most managers, 344 (68\%), described their relationship towards their subordinates as professional but friendly, followed by 128 (25\%) describing the relationship as friendly and open. This suggests concern for people, tendency to trust the employees and use of cooperative style of management. When asking about the relationship towards their superiors, slightly lower number of respondents, $316(61 \%)$, described it as professional but friendly, and $104(20 \%)$ described it as friendly and open. This upward relationship is checked to see whether the person is consistent in his/her orientation and also to eliminate the error that can be made by overestimating one's style. Even though the number is lower when the focus is upward rather then downward, we can see that these are still two significant types of responses. However, looking at the questions individually does not indicate consistency of the style towards the subordinates and superiors. Therefore, to have a more detailed picture, we have compared these two sets of responses to see how many people indicated the same response both in relation to subordinates and superiors (as presented in Table 3).

Table 3. Comparison of alignment of responses to questions 31 and 35

\begin{tabular}{|c|c|c|c|c|}
\hline & $35-\mathrm{A}$ & $\mathbf{3 5 - B}$ & $35-\mathrm{C}$ & $\mathbf{3 5 - D}$ \\
\hline $31-\mathrm{A}$ & $46.88 \%$ & $47,66 \%$ & $8,59 \%$ & $2,34 \%$ \\
\hline $31-\mathrm{B}$ & $12,21 \%$ & $\mathbf{7 3 , 2 6} \%$ & $14,53 \%$ & $2,91 \%$ \\
\hline $31-\mathrm{C}$ & $19,23 \%$ & $34,62 \%$ & $42,31 \%$ & $7,69 \%$ \\
\hline $31-\mathrm{D}$ & $0,00 \%$ & $37,50 \%$ & $25,00 \%$ & $37,50 \%$ \\
\hline
\end{tabular}

We have found the largest correspondence $(73,26 \%)$ in the answer indicating that the managers prefer professional but friendly relationships both upwards and 
downwards. The second largest correspondence $(46,88 \%)$ has been in the response classifying the relationship with both superiors and subordinates as friendly and open. This shows that managers have a need to cooperate in both directions within the organization, perceiving their employees as well as their bosses as cooperative and professional.

\subsection{Work Relationships Outside the Workplace}

To examine the attitude of managers regarding the issue of building, accepting, or sustaining relationships with their subordinates and superiors outside the workplace, we have looked into the questions number 39 and number 41, which were stated as follows and to which the same possibilities for answers were presented:

\section{Question 39: Do you meet with subordinates in} your free time?

Question 41: Do you meet with your superiors in your free time?

a) no, I do not seek such opportunities

b) no, the organization does not provide such opportunities

c)yes, at formal meetings and events

d) yes, I personally initiate such opportunities

e)yes, but sometimes 'less would mean more'

Building and supporting the existence of informal relationships that exceed the boundaries of workplace is often considered to be a positive attitude and a demonstration of people orientation.

When asked to evaluate their attitude towards spending free time with their subordinates, $142(26,60 \%)$ indicated that they do not seek such opportunities. There were $61(11,42 \%)$ managers who suggested that they do not meet their subordinates, as the company does not provide such occasions. The response representing that the managers meet their subordinates in their free time at formal meetings was marked by 205 $(38,39 \%)$ respondents. The answer (d) was marked in $98(18,35 \%)$ responses. The last response (e) indicates that the manager spends his/her free time with subordinates but believes that "less would mean more", in other words that he/she maybe feels some burden of these out of work activities. Here, $28(5,24 \%)$ responses were marked.

When asked to evaluate their attitude towards spending free time with their superiors, the following answers were recorded: a) $146(28,46 \%)$
b) $73(14,23 \%)$
c) $249(48,54 \%)$
d) $34(6,62 \%)$
e) $11(2,14 \%)$

There were altogether 498 respondents who indicated sole answers to questions 39 and 41 . Here, we have looked into the individual responses, eliminating multiple responses, and we have compared them to see whether there is any agreement in the way the managers respond upwards and downwards (as presented in the Table 4).

Table 4: Comparison of alignment of responses to questions 39 and 41

\begin{tabular}{|l|r|l|l|l|l|}
\hline & $41-\mathrm{A}$ & $41-\mathrm{B}$ & $41-\mathrm{C}$ & $41-\mathrm{D}$ & $41-\mathrm{E}$ \\
\hline $39-\mathrm{A}$ & $20.88 \%$ & $2.21 \%$ & $5.02 \%$ & $0,00 \%$ & $0,00 \%$ \\
\hline $39-\mathrm{B}$ & $1.41 \%$ & $8.43 \%$ & $2.61 \%$ & $0,00 \%$ & $0,00 \%$ \\
\hline $39-\mathrm{C}$ & $4,02 \%$ & $2.41 \%$ & $34,94 \%$ & $3.01 \%$ & $0.20 \%$ \\
\hline $39-\mathrm{D}$ & $2.81 \%$ & $1,61 \%$ & $11,24 \%$ & $6.22 \%$ & $0,80 \%$ \\
\hline $39-\mathrm{E}$ & $1.41 \%$ & $0,80 \%$ & $2.21 \%$ & $0.00 \%$ & $1,41 \%$ \\
\hline
\end{tabular}

The largest consistency in responses $(34,94 \%)$ can be seen in the most neutral answer, showing that managers, in their free time, meet with their subordinates as well as superiors on formal occasions and parties. The second most frequent concord $(20,88 \%)$ is seen in the answer (a) indicating that the managers do not seek or initiate occasions to meet with their subordinates or superiors in their free time.

\section{Conclusions and Implications for Further Research}

The presented paper argues that there is a shift in managerial style in Slovakia. Upon analyzing the collected data, we conclude that the style of management can be described as cooperative and participative, stressing both the importance of achieving goals and importance of developing good interpersonal relationships with people at the workplace. As a style of management, this is suitable in an unstable environment, where there is a constant need for flexibility and change.

We also conclude, based on the findings, that managerial style of Slovak managers is balanced in its orientation towards both goals and people, indicating that the managers are responsive to the external influences caused by the shift towards tournament business environment. The style also suggests, that the introduction of HR practices, common in the environment that supports the same managerial style, are facilitated in Slovakia. Moreover, the findings indicate, that organizations have been building managerial talent that re- 
sponds to the demands of a tournament environment. To enhance the positive attitude of managers, the organizations should also implement behavioral and competence oriented performance appraisal methods, design performance-related compensation models, career counseling and offer training and development programs designed for interpersonal skills as well management by objectives.

On the other hand, the organizations should build on this knowledge by designing and promoting HR policies that are consistent with an open, goal oriented style of management.

The findings of this study contribute to on-going efforts to understand the nature of managerial work and the link between style of managers and formal organizational processes. The paper describes the managerial style within rapidly evolving corporate environment of Slovakia, a country in the region of Central and Eastern Europe (CEE). A longitudinal study, however, would depict in more detail the particular changes in managerial style from autocratic towards participative.

\section{References}

1. Weidlich R. Market Pressures for Tournament Type of Organization in Emerging Central Europe: Evidence, Implications and Sustainability. In: Proceedings of the $6^{\text {th }}$ International Conference on Global Business and Economic Development; States and Markets: Forging Partnerships for Sustainable Development. Bratislava, 2001.

2. Blake R. R. and Mouton J. S. The New Managerial Grid. Houston: Gulf Publishing Company, 1978, p. 126-133

3. Blake R. R. and Mouton J. S. A Comparative Analysis of Situationalism and 9,9 Management by Principle. In: Organizational Dynamics. Spring, 1982, p. 21-23.

4. Blake R. R. and Mouton J. S Blake. Leadership DilemasGrid Solutions. In: Kreitner R. and Kinicki A. Organizational Behavior. Irwin McGraw Hill. 1998, p. 502.

5. Luptakova S. and Vargic B. (2001). Communication in Slovak Organizations in Relations to Power Distance Dimension of Slovak National Culture. In: Proceedings of the 6th International Conference on Global Business and Economic Development; States and Markets: Forging partnerships for sustainable development. Bratislava. 2001. 